\title{
Reseña selectiva del Coloquio-Panel sobre: El futuro de los carbones españoles
}

Prof. Dr. JOSE CALleJA - CSIC/IETCC

$R E S U M E N$

Por su repercusión general y en la Industria Española
del Cemento en particular, dadas las condiciones
energéticas actuales y futuras previsibles,
se da cuenta en esta Reseña del contenido del citado
Coloquio-Panel, muy especialmente por lo que
a la mencionada industria puede afectar,
en lo que respecta a la utilización de carbones
nacionales y/o de importación, y a sus
calidades, precios y suministros -cantidades,
puntualidad, regularidad-, habida cuenta
de las necesidades especificas de la industria cementera
en lo referente a la utilización de combustibles
sólidos, con vistas a la economía y buena
marcha del proceso de clinkerización
y a la calidad de los cementos resultantes.
$S U M M A R Y$

\author{
Taking into account the general importance \\ of the item showed in the title, and more \\ particularly that concerning the Spanish \\ Cement Industry considering the present and future \\ energetic circumstances, this report presents \\ the content of the mentioned Colloquim \\ on "The Future of the Spanish Coals". \\ Special mention is made to the use of national \\ and imported coals according to their qualities, \\ prices and supplies, taking into account \\ the specific needs of the cement industry, \\ as far as the use of solid fuels is concerned, \\ with respect to the economic operation \\ of the clinkering process and the good \\ quality of the resulting cements.
}

\section{INTRODUCCION}

El Coloquio-Panel sobre "El Futuro de los Carbones Españoles" ha sido continuación lógica y obligada de los organizados previamente por la ANQUE (Asociación Nacional de Químicos de España -Delegación Centro-) y por el Colegio Oficial de Químicos de Madrid, con la colaboración de la Delegación de Asturias y León de la ANQUE y del Colegio Oficial de Químicos de AsturiasLeón, así como de la Cátedra de Fisicoquimica de Procesos Industriales, de la Universidad Autónoma de Madrid. Los anteriores Coloquios-Paneles fueron dos y versaron sobre "El Futuro de los Combustibles Líquidos y Gaseosos: Horizonte Año 2000", y sobre "Energía Nuclear", respectivamente.

Este tercer Coloquio-Panel se celebró en el Hostal de San Marcos de León, durante los días 16, 17 y 18 de Septiembre de 1982, actuando de coordinador, como en los anteriores, el Prof. Dr. Pedro LUIS y LUIS, Presidente de la Sección de Energía de la ANQUE y Agregado en la Cátedra antes mencionada.

La elección de León como sede ha sido, por razones obvias un acierto, dada la importancia de la cuenca minero-carbonifera de la zona, entre otras de la geografía nacional.

Como era de esperar, dada la naturaleza del tema, han intervenido en el Coloquio como Presidentes de Sesiones, como Ponentes o como participantes en Paneles y Coloquios, destacadas personalidades de importantes Sociedades y Empresas Mineras del Carbón, Termoeléctricas, Siderúrgicas, Cementeras, Cerámicas, etc. (HULLERA VASCO-LEONESA, ENCASUR, EMPRESA NACIONAL ADARO DF. INVESTIGACIONES MINERAS, S. A., PRO- 
MOTORA DE MINAS DE CARBON, S. A., HUNOSA, SENER, FENOSA, F. L. SMIDTH Y CIA. ESPAÑOLA, S. A., ENSIDESA, TECNICAS REUNIDAS, S. A., ASLAND, S. A., CEMENTOS ALBA, S. A., CERAMICA DEL NALON, CARBOEX, CARELEC, CEMENTOS DEL NORTE, citadas por orden de aparición en el Programa), así como de Organismos y Centros Oficiales o Paraestatales de Investigación (UNIVERSIDAD COMPLUTENSE -Cátedra de Fisicoquimica de Procesos Industriales-, ESCUELA TECNICA SUPERIOR DE INGENIEROS DE MINAS DE MADRID -Cátedra de Tecnologia de Combustibles-, CONSEJO SUPERIOR DE INVESTIGACIONES CIENTIFICAS -Instituto Nacional del Carbón, Instituto Nacional de Carboquimica, Instituto "Eduardo Torroja" de la Construcción y del Cemento, Instituto de Cerámica y Vidrio-, JUNTA DE ENERGIA NUCLEAR, INSTITUTO NACIONAL DE INDUSTRIA, asimismo citados por orden de aparición en el Programa).

\section{CONTENIDO DEL COLOQUIO-PANEL}

El contenido del Coloquio-Panel quedó recegido en una Presentación, una conferencia Inaugural, seis Sesiones con sus correspondientes Ponencias y Coloquios, una Sesión dedicada a las Conclusiones, una Conferencia Final y un Acto de Clausura.

La Conferencia Inaugural, con el titulo de "La experiencia española de dos siglos como base para el futuro desarrollo de la mineria del carbón", corrió a cargo de D. Antonio DEL VALLE MENENDEZ, Presidente de la Sociedad Hullera Vasco-Leonesa.

Las seis Sesiones respondieron a los títulos y Presidencias siguientes:

Sesión I: "Los recursos españoles de carbón; distribución y calidades".

Presidente: D. Juan Ignacio ARTIEDA BOSQUETS.

Vicepresidente Ejecutivo de ENCASUR.

Sesión II: "Explotación racional de los carbones españoles".

Presidente: D. José Manuel FERNANDEZ FELGUEROSO.

Presidente de HUNOSA.

Sesión III: "Tecnologias en desarrollo y posible aplicación a los carbones españoles".

Presidente: D. Antonio CANSECO MEDEL.

Catedrático de Tecnología de Combustibles (Escuela Técnica Superior de Ingenieros de Minas, Madrid).

Sesión IV: "Industrias Básicas del Carbón" (Centrales Eléctricas - Siderurgia- Calderas de Vapor y Otros Usos).

Presidente: D. José Ramón GARCIA CONDE.

Director del Instituto Nacional del Carbón. Oviedo.

Sesión V: "Industrias Básicas del Carbón".

(Industria del Cemento e Industria Cerámica).

Presidente: D. José CALLEJA CARRETE.

Ex-Vicedirector del Instituto "Eduardo Torroja" de la Construcción y del Cemento -del CSIC- Madrid.

Sesión VI: "Perspectivas Internacionales de Producción, Comercio y Utilización del Carbón".

Presidente: D. José SIERRA LOPEZ.

Presidente de CARBOEX. 
Las Ponencias presentadas a estas Sesiones fueron: 3 a la I, 3 a la II, 4 a la III, 8 a la IV, 6 a la $\mathrm{V}$ y 4 a la VI; en total, 28, más una incluida en la III, fuera de programa.

Se celebraron conjuntamente los coloquios de las Sesiones I y II; los de las demás por separado, actuando en todos los casos como moderadores los propios Presidentes de las respectivas sesiones.

Por su interés más destacado para los Sectores Cementero y Cerámico españoles se da cuenta en lo que sigue, con el detalle propio de un resumen, del desarrollo de la Sesión $\mathrm{V}$ relativa a ambos sectores industriales.

\section{CONFERENCIA INAUGURAL}

"La experiencia española de dos siglos, como base para el futuro desarrollo de la minería del carbón". Antonio DEL VALLE MENENDEZ

Se trató de una documentada y ordenada exposición deì desarrollo histórico de la Minería del Carbón, desde el punto de vista del Derecho Minero, en su proyección sobre la Producción, la Ciencia y la Tecnología Industrial, el Mercado, la Sociología y la Politica.

Arrancó el conferenciante de la crisis enegética más reciente, con su secuela, como en todas las anteriores, de intentar ahorros de energía y de utilizar nuevas fuentes de la misma. Situó el primer mercado del carbón en el desarrollo de la industria siderúrgica, con lo cual se plantearon los problemas tecnológicos del laboreo de las minas, incrementados y agudizados después por la extensión de ese mercado a las explotaciones ferroviarias.

El desarrollo de la utilización industrial del carbón -expuso- da origen al paralelo del correspondiente Derecho, cun sus sucesivas Ordenanzas y Leyes, de las cuales el conferenciante hizo una detallada exposición cronológica. Entreverada con la misma hizo también una descripción del desarrollo del pensamiento y de las conquistas científicas y técnicas, así como de la cultura general en España, en Europa y en el Mundo, a través de los protagonistas más destacados de dicho desarrollo, tanto estudiosos como politicos. En tal sentido puso el énfasis en los acontecimientos, acciones, creaciones, enzidades y personas que, ya desde el siglo XVII, y prácticamente desde las postrimerias del XVIII, situaron a España en la ruta de la Ciencia, de la Técnica y del Progreso. Ruta que fue obstruida por la Guerra de la Independencia.

Tras de ésta, y a partir del comienzo del segundo tercio de la centuria del XIX, cambiaron -según el conferenciante- las relaciones de producción en España, por una serie de factores que pasó a analizar; todo lo cual propició el proceso de industrialización posterior del pais, siendo los sectores siderúrgico y minero unos de los más dinámicos en el decenio de los 60 de dicha centuria, y estando perfectamente localizados en las Provincias Vascongadas, Asturias y León. Con el destacado papel a cuyo desempeño estaba llamado el carbón en tal proceso de industrialización, surgió la primera Ley de Minas de 1825, con antecedentes en las Pragmáticas de Felipe II promulgadas en 1584, y con consecuentes intermedios de los últimos años del siglo XVIII. A esta Ley siguieron otras hasta la de 1938, las cuales influyeron en el desarrollo de las explotaciones carboneras.

El conferenciante discurrió después por las Leyes de Minas de 1944, 1969 y 1973 y del Fomento de la Minería de 1977, analizando la de 1973 título a título y señalando que la promulgación de la misma prácticamente coincidió con el advenimiento de la crisis de la energía, lo que dio lugar a la creación en España del PEN (Plan Energético Nacional), el cual derivó en la Ley de 1980, "miniley minera", en la que se insertó una Sección D que incluía carbones, minerales radiactivos, recursos geotérmicos, rocas bituminosas y cualesquiera otros recursos geológicos de interés energético. 
Trató después el expositor de la Ley de 1980, y tanto a partir de ella como de la evolución de las anteriores, hizo un análisis de las modificaciones experimentadas por la configuración de la concesión minera, dado que constituye la base de las sociedades, siendo por lo tanto un factor determinante de las decisiones empresariales.

Analizó el conferenciante a continuación las Series cronológicas del desarrollo de la Industria Carbonera, dentro de cada Ordenamiento Jurídico, desde la primera, caracterizada por el Liberalismo (que comienza de 1830 a 1914 y termina de 1930 a 1936 coincidiendo con la Segunda República, pasando por las etapas de la Primera Guerra Mundial de 1914 a 1918 y de la Dictadura de 1923 a 1929), en la cual, con altibajos sobre todo en los últimos períodos, se manifiesta una tendencia primero al crecimiento y después a la estabilización de la producción, entre prácticamente nula al principio y del orden de los 7 millones de toneladas/año al final.

En la segunda Serie, que se extendió desde 1937 a 1957 caracterizada por la Postguerra y la Recuperación, hasta 1958 a 1977 caracterizada por el tránsito de la Estabilización a la Planificación, la producción manifestó una tendencia al crecimiento entre 1940 y 1958, desde 8 a 17 millones de toneladas/año, con una recesión entre 1959 y 1976, período en el que, con fluctuaciones, se descendió a unos 14,5 millones de toneladas/año, y con una recuperación hasta unos 18 millones en 1977.

En la tercera Serie, caracterizada por la Transición Política entre 1978 y 1981, la producción total de carbón pasó de unos 20 a unos 35 millones de toneladas/año, incrementada principalmente por los lignitos pardos (que en dicho periodo pasaron de unos 5 a unos 15 millones de toneladas/año, es decir, casi a la mitad de la producción total de carbón en el mismo, y a la total de los años 1958 y 1977).

El expositor trató después de la evolución de los efectivos humanos adscritos al Sector Minero del Carbón durante las tres Series Cronológicas, los cuales pasaron, en números redondos, de cerca de 100.000 en 1950 a poco más de 50.000 en 1980 (prácticamente la.mitad en 30 años). A su juicio, esta reducción de plantilla, el incremento de la producción con los consiguientes almacenamientos de carbón que al 31-XII-80 se elevaban a unos 14 millones de toneladas (el 40 por ciento de la producción de dicho año), y el aumento de los salarios por encima de las tasas de inflacción, han ensombrecido el panorama de las cuencas carboniferas.

El conferenciante señaló una falta de adecuación entre estimaciones y resultados, relativos ambos a la producción de carbón, dentro del PEN, habiéndose propugnado entre 1977 y 1978 un aumento práctico del 100 por ciento (de unos 18 a unos 36 millones de toneladas) para lo cual se apuntó una serie de medidas concretas de gobierno (las cuales pasó a glosar), de las que pocas se han cumplido, salvo la propia del aumento de producción en una medida aceptable, y al margen de las acciones previstas.

Finalizó su exposición el Sr. DEL VALLE diciendo que la experiencia pasada ha mostrado que los objetivos del Sector Minero del Carbón han sido los aumentos de producción y las normas de protección de la misma. Y que para ello, y con vistas al presente y al futuro, hay que llevar a cabo una serie de actuaciones, de las que mencionó seis, relativas a libertad, proteccionismo y fiscalidad, a otorgamiento de concesiones mineras, a planificación de la producción en relación con la demanda y la inversión, a la relación entre recursos de carbón y costos de extracción, a la evolución técnica de las aplicaciones del carbón, y a una política realista de precios energéticos en origen. En cada caso señaló las ventajas e inconvenientes, así como la procedencia o improcedencia de unas u otras acciones, en función de los tiempos y de la situación actual.

Por último consideró aspectos ecológico-ambientales, socio-económicos y administrativo-regionales en relación con la industria minera y las cuencas carboniferas explotables, concluyendo que la experiencia de dos siglos, tal como figura en el título de su conferencia, puede ayudar a fijar un 
marco de actuación en el que pueda ejercer su acción futura la libre empresa minero-carbonera sobre principios que incluyen humanismo y participación.

\section{DESARROLLO DE LA SESION V: Industrias Básicas del Carbón: CEMENTO Y CERAMICA}

A las 4 de la tarde del viernes dia 17 de Septiembre de 1982 comenzaron las tareas de la Sesión V del Coloquio-Panel sobre "El Futuro de los Carbones Españoles", dedicada a las Industrias Básicas del Carbón, y dentro de ellas a las del Cemento y la Cerámica.

La sesión se desarrolló de acuerdo con el siguiente Programa, consistente en una Introducción, cuatro Ponencias sobre Cemento y dos Ponencias sobre Cerámica.

0. Introducción General a los temas, por el Presidente de la Sesión, Prof. Dr. José CALLEJA CARRETE, del Consejo Superior de Investigaciones Cientificas -CSIC- (Instituto "Eduardo Torroja" de la Construcción y del Cemento -IETCC-).

A continuación, exposición de las Ponencias sobre cemento, conforme al orden siguiente:

1. Primera Ponencia sobre "El Carbón como Combustible en la Industria del Cemento", por el Dr. Julio PEREZ ALONSO, de la Cia. ASLAND.

2. Segunda Ponencia sobre la "Fabricación de Cemento con Carbones, y Sistemas de Clinkerización pasados y presentes", por el Lcdo. Juan José ALONSO OBESO, de la firma Cementos ALBA, S. A.

3. Tercera Ponencia acerca del "Aprovechamiento de Estériles de Carbón para la Industria del Cemento en el Reactor "THAGARD", a cargo del Dr. Jacinto MONGE GUTIERREZ, de la Empresa HUNOSA.

4. Cuarta Ponencia acerca de la "Influencia de los Componentes Minoritarios de los Carbones en la Fabricación de Cementos", por el Prof. Dr. Francisco SORIA SANTAMARIA, del CSIC/IETCC.

Seguidamente tuvieron lugar las exposiciones de las Ponencias sobre Cerámica, de acuerdo con el siguiente orden:

5. Quinta Ponencia sobre el "Empleo del Carbón en la Industria Cerámica de Ladrillos de Construcción", a cargo del Prof. Dr. Antonio GARCIA VERDUCH, del Consejo Superior de Investigaciones Cientificas -CSIC- (Instituto de Cerámica y Vidrio).

6. Sexta Ponencia acerca del "Empleo del Carbón en la Industria Cerámica en General", por el Ing. Angel FOMBELlA GONZALEZ, de la firma CERAMICA DEL NALON.

De todo lo relativo al cemento se da cuenta a continuación, en forma de breve resumen.

\subsection{Introducción general a los temas, por el Prof. Dr. José CALLEJA}

En la Introducción a los temas de la Sección V el Prof. CALLEJA comenzó agradeciendo, en nombre propio y en el del panel de la misma, a la Asociación. Nacional de Químicos de España (ANQUE) -Delegación Centro y de Asturias y León-, y a los Colegios Oficiales de Químicos de Madrid y de Asturias-León, la acogida dada en el marco del Coloquio-Panel a los representantes de las Industrias del Cemento y de la Cerámica. 
Consideró que en dicho marco no podía faltar la presencia de las mencionadas industrias, como básicas consumidoras de carbón en no pequeña escala.

Pasó enseguida a dar unas coordenadas de la situación presente de la Industria Cementera, para orientación de los desconocedores de la misma y puesta al día de los que de algún modo la conocen.

Hizo destacar el hecho de que la Industria Española del Cemento ocupa el cuarto lugar entre los países de la Europa Occidental miembros del CEMBUREAU, y el séptimo mundial en cuanto a capacidad de producción se refiere.

Señaló por otra parte -y esto es quizás lo más importante-, que España es, con mucho, el primer pais exportador de cemento del mundo, con un volumen de exportación de clínker y de cemento que a finales de 1982 alcanzaría la cifra de los 13 millones de toneladas, lo que supone casi la mitad de la producción real en la actualidad, la cual, con unos 28 millones de toneladas, se sitúa en el presente alrededor del $70 \%$ (en promedio) de la capacidad total de producción - que, en números redondos, es de unos 38 millones de toneladas/año-.

Indicó también que el consumo térmico en la producción de clínker es de unas $800-850 \mathrm{kcal} / \mathrm{kg}$ (en promedio entre unas 750 y $\mathrm{i} .200$ ), siendo el consumo total de 20 a 25 billones de kcal para una producción de 28 millones de toneladas de clinker aproximadamente. Esto puede suponer alrededor de 35 a 40 millones de toneladas de carbón de unas $6.000 \mathrm{kcal} / \mathrm{kg}$ de potencia calorifica, y unos 2 a 2,5 millones de toneladas de fuel-oil con potencia calorifica de unas $10.500 \mathrm{kcal} / \mathrm{kg}$. Muy grosso modo se puede considerar, por lo tanto, que una tonelada de clínker consume unos $125 \mathrm{~kg}$ de carbón o unos $85 \mathrm{~kg}$ de fuel-oil, siempre por término medio.

Agregó que a estos consumos había que añadir el de unos $100 \mathrm{kWh}$ por molienda de clínker, más los correspondientes a la extracción de materias primas y preparación y transporte de diversos materiales; energía que, si de una forma u otra procede de centrales térmicas de carbón o de derivados del petróleo, supone un consumo aún mayor de toneladas equivalentes de carbón por tonelada de clínker producida.

En cuanto a la evolución de la utilización de los combustibles en la cementería española, detalló que había sido la siguiente:

- Durante los decenios 40 y 50, por no remontar los datos al periodo anterior al cuatrienio 19361939 , se quemaban en la industria cementera carbones casi exclusivamente nacionales, de muy baja y muy variable calidad, a veces con más del 50 por ciento de cenizas.

- Durante la década de los 60 tuvieron lugar, simultánea o sucesivamente, la transformación de las instalaciones y el paso del uso del carbón al del fuel-oil, y la modernización de la tecnología y de la maquinaria -hornos, molinos y captadores de polvo-, con la supresión prácticamente total de los hornos verticales y el reequipamiento -o la eliminación- de las fábricas más antiguas $u$ obsoletas en cuanto a procesos e instalaciones. En esta época tuvo lugar también una importación masiva de cemento procedente prácticamente de la totalidad de los paises del Este de Europa -Polonia, Checoslovaquia, Hungria, Yugoslavia, Rumania, Bulgaria- y hasta de Israel. Como dato curioso anecdótico se señaló que, a la sazón, el cemento portland de Israel, de buena calidad, se ponía en el puerto de Sevilla a precio inferior al del producido en la zona.

- En el decenio de los 70, a partir del 73 y con motivo de la crisis energética en general y del petróleo en particular, se prodigan y aceleran los pasos de la restante via húmeda a la vía seca, y se inicia el retorno al empleo del carbón en lugar del fuel-oil. 
- En los corrientes años 80 sigue adelante el retorno, habiéndose alcanzado ya posiblemente más del 85 por ciento de la reconversión al carbón, combustible en cuya utilización la industria cementera española tiene -tenia, al menos- una grande y buena experiencia.

Hoy dia, -añadió-, mediante los nuevos sistemas de horno -con precalcinación- y de intercambiadores de calor en vía seca -mediante ciclones-, desarrollados en los años 60 y 70, se ha logrado rebajar los consumos térmicos hasta las $740 \mathrm{kcal} / \mathrm{kg}$ de clínker, más o menos.

Como consecuencia de una serie de factores ligados a la citada situación de procesos y maquinaria instalada en las fábricas, la reconversión de fuel-oil al carbón impuso unas calidades de éste junto a una regularidad de las mismas, unas necesidades de almacenamiento y reservas y una garantía de suministro, que obligaron a la importación de carbón, prácticamente de los cinco continentes: Europa (Inglaterra y Polonia), Asia (República Popular de China), Africa (del Sur), América (EE.UU) y Oceanía (Australia), principalmente.

La mayor parte de las importaciones -continuó- se han hecho y hacen a título individual, por parte de cada fábrica o empresa. Se ha hablado de una solución genérica sectorial, a base de una política oficial de importación de carbones, pero semejante solución, de existir, -lo cual es dudoso-, no sería eficaz en general, dado que cada fábrica necesita su propio carbón, con unas características dadas, que puede muy bien no ser apto para otras fábricas. En tal sentido, un sistema intermedio consistente en la agrupación de fábricas de parecidas caracteristicas en cuanto al carbón que necesitan, y cuando las razones geográficas de situación lo permiten, podria ser una solución basada en una importación conjunta. Y tanto más cuanto que la importación por una sola de ellas de fletes de 50.000, 80.000 ó más de 100.000 toneladas supondría graves inconvenientes por razones de espacio de almacenamiento, de inmovilización de capital y de mermas de calidad con peligro de autoencendido, etc.

En todo caso - prosiguió- existen siempre problemas de calidad, de necesidad de proceder a mezclas adecuadas, de estaciones portuarias de recepción, de transporte y distribución (particularmente a fábricas del interior del pais, por el gran número de unidades de transporte de RENFE u otras que serian necesarias, y que no siempre estarian disponibles), etc.

A juicio del expositor, una solución colectiva y tal vez ideal, sería la consistente en consumir el máximo posible de carbón nacional, quizás en mezclas bien estudiadas con carbones de importación -en caso necesario-, de forma que quedaran satisfechos al máximo (si bien que parcialmente) los intereses de los dos sectores implicados: el Cementero y el Minero de Carbón. Es solución que se deberia buscar y se podría encontrar y aplicar de forma progresiva, para lo cual sería preciso emprender los correspondientes estudios y desarrollar la investigación necesaria.

El expositor mencionó de pasada algunos de los factores técnicos de los carbones que inciden de una u otra forma en la fabricación del clínker. Citó la calidad, centrada en la potencia calorifica, en las cenizas y en los volátiles, así como en los componentes minoritarios u oligocomponentes de los carbones, como azufre, cloro y álcalis, principalmente. Se refirió a su influencia en la calidad del clinker, en la marcha del proceso de combustión y calcinación según los diferentes sistemas de producción y de hornos, en la formación de recubrimientos, adherencias y anillos, en el desgaste y estabilidad de los revestimientos refractarios en las distintas zonas de los hornos, en los rendimientos del proceso de clinkerización y en la productividad, etc., por dar una idea de la gran importancia que en los múltiples aspectos de la fabricación del cemento tienen las caracteristicas del combustible empleado.

Añadió que el tratamiento de todos los puntos mencionados, y de otros más, era el objeto de la Sesión V del Coloquio-Panel, y que en ello habian colaborado eficazmente los ponentes con la presentación de sendos trabajos. Dijo que entre los ponentes los habia de distinta condición: Investigadores del CSIC. como los Profs. Dres. SORIA y GARCIA VERDUCH (y el propio 
Presidente de la Sesión V), Investigadores de empresas privadas, como los Dres. PEREZ ALONSO y MONGE, y Técnicos de Fabricación y Control, como el Licdo. ALONSO OBESO, $\mathrm{y}$ el Ing. FOMBELLA.

Después de señalar la obligada limitación de tiempo para las exposiciones, a fin de brindar a los oyentes el mayor posible para el Coloquio, que como Presidente deseaba fuese extenso y fructifero, dio la palabra al primer ponente, según el Programa.

\subsection{1. ${ }^{a}$ PONENCIA, por el Dr. Julio PEREZ ALONSO, de la Cía. ASLAND, S. A.}

\section{"El carbón como Combustible en la Industria del Cemento".}

Consideró el ponente en su introducción al tema la utilización del carbón en la fabricación de cemento durante los años 40 y 50 , y su sustitución por el fuel-oil y el gas natural durante el decenio 60-70, por mejor precio y calidad de éstos y mayor regularidad en el proceso y marcha de los hornos, con la repercusión favorable en la calidad del clinker.

Mencionó que la crisis de la energía a comienzos de los 70 desniveló los precios del fuel-oil, de tal modo que a partir de 1979 se planteó el retorno de las fábricas al uso del carbón, incrementándose éste en 1980 y máas aún en 1981, con la esperanza de que los combustibles sólidos llegasen a alcanzar y rebasasen la cifra del $80 \%$ del consumo total de combustible en el sector cementero -cosa que, en efecto, se ha logrado-

A continuación se ocupó de los sistemas de instalaciones para los procesos de secado y molienda del carbón, los cuales, en general, se realizan conjuntamente en el molino de carbón.

Según el acoplamiento del sistema de molienda del carbón con el de combustión de éste en el horno, el ponente citó tres procedimientos de combustión: directa, indirecta y semidirecta -intermedia-, exponiendo las ventajas e inconvenientes de cada una en función del costo de instalación, de la sencillez de operación, del consumo térmico específico, de las paradas del molino de carbón, de los riesgos de explosiones y fuegos con determinados carbones y del contenido de humedad de éstos, y señalando los criterios para la elección de uno u otro.

A continuación trató sucesivamente de los procesos de molienda y secado, combustión, y operación del horno. En cuanto al primero, señaló que es primordial la temperatura de los gases de secado para evitar combustiones y explosiones, en función de los contenidos de cenizas y volátiles y de la finura del carbón.

La temperatura debe ser tal que deje una cierta humedad residual en el carbón (de 0,5 a 1,5\%), y del orden de 60 a $80^{\circ} \mathrm{C}$ para volátiles comprendidos entre 22 y $28 \%$. A menor proporción de volátiles debe corresponder, evidentemente, una mayor finura de molido para facilitar la combustión.

Respecto de ésta, el conferenciante señaló los parámetros de la misma: proporción y mezcla adecuadas entre aire primario y carbón, granulometría idónea de éste y temperatura apropiada para la ignición.

Al describir la llama indicó el orden de combustión de los componentes del carbón en la misma: volátiles, gases formados, carbono fijo y coque, fijándose la longitud de llama entre el desprendimiento de los volátiles (ignición) y la combustión del coque con formación de cenizas, de tal modo que a menor contenido de volátiles y mayor de cenizas corresponde una luminosidad menor, para una mayor distancia de ignición y una longitud mayor de llama, por lo cual es preciso moler más finamente los carbones pobres en volátiles y ricos en cenizas para acortar ambas lo necesario y para aumentar la radiación de la llama. Una menor cantidad de aire primario por 
debajo de $22-24 \%$ y una mayor turbulencia del mismo contribuyen también, sobre todo la primera, a acortar la llama, pero aumentando la distancia de ignición.

En relación con el consumo calorifico, la duración del refractario y la formación de anillos en los hornos, problemas intimamente ligados a la naturaleza de los carbones, el ponente señaló:

i) por lo que respecta a la emisión de la llama, mayor en la de carbón que en la de fuel-oil y en ésta que en la de gas, a igualdad de otros parámetros parecia que el menor consumo calorífico correspondería a un horno de carbón, lo cual es cierto si el carbón es escaso en cenizas, y no lo es si abunda en ellas, si bien en el primer caso se reduce la duración del refractario, cosa que también sucede si el carbón es demasiado fino, a igualdad de todo lo demás;

ii) en relación con los anillos, éstos se forman a la entrada de la zona de sinterización -formación de fase líquida en cierta proporción-, dependiendo de la composición, regularidad y homogeneidad del crudo, de la proporción y naturaleza de las cenizas del carbón (determinantes de la temperatura eutéctica de aquél, de modo que a menor contenido de cenizas y mayor temperatura eutéctica menor es la probabilidad de formación de anillos), y de la conducción de la combustión en el horno (forma y tipo de llama).

En este aspecto insistió el ponente en la importancia de la composición de las cenizas en su fusibilidad y fluidez, y consecuentemente en su capacidad para formar anillos: ésta es tanto menor cuanto mayores son aquéllas, tanto determinadas experimentalmente como calculadas por indices químicos.

Terminó señalando la distinta influencia de las cenizas del carbón según el tipo de horno: en el de intercambiadores su absorción puede llegar a ser del $100 \%$, sin más problemas que el del ajuste de la composición del crudo; mientras que en el Lepol pueden influir desfavorablemente, o bien en la granulación del crudo y en la estabilidad de los gránulos, o bien en la calidad de éstos al acumular cal libre cuando se eleva el grado de saturación de cal del crudo para contrarrestar el efecto ácido de las cenizas.

La ponencia se puede resumir como el énfasis de su autor en la importancia de la calidad de los carbones, y en particular de la proporción y naturaleza de sus cenizas en la marcha de la combustión y de la clinkerización, en la formación de anillos, en el rendimiento térmico del proceso, en la duración del refractario y en la calidad del clínker, en relación con distintos tipos de hornos.

3.3. 2. ${ }^{\text {a }}$ PONENCIA, por el Licdo. Juan J. ALONSO OBESO, de CEMENTOS ALBA, S. A.

\section{"Fabricación de Cementos con Carbones y Sistemas de Clinkerización pasados y presentes"}

El ponente comenzó haciendo historia del paso del carbón al fuel-oil y del retorno de éste al carbón en la industria española del cemento, entre los años 50 y 70, y en los que van del decenio del 80, respectivamente. El máximo consumo absoluto de fuel-oil se alcanzó en 1978 (2.456.352 t) y el específico en 1979 (90 kg/t de clínker), mientras que los correspondientes mínimos consumos de carbón fueron el absoluto de $262.237 \mathrm{t}$ en 1979 y el específico de $9,7 \mathrm{~kg} / \mathrm{t}$ de clínker en 1978 y 1979. El descenso de los consumos absolutos y específicos de fuel-oil entre 1980 y 1981 fue de $2.128 .085 \mathrm{t}$ a $1.514 .152 \mathrm{t}$, y de $86,3 \mathrm{~kg} / \mathrm{t}$ de clínker a $57,9 \mathrm{~kg} / \mathrm{t}$ de clinker, respectivamente, mientras que los correspondientes incrementos de los consumos de carbón fueron de $299.800 \mathrm{t}$ a $1.675 .536 \mathrm{t}(459 \%)$ y de $12,2 \mathrm{~kg} / \mathrm{t}$ de clinker a $64,0 \mathrm{~kg} / \mathrm{t}(525 \%)$. En 1982 estas cifras se han desproporcionado mucho más.

En cuanto a los sistemas de secado, molienda c inyección de carbón en el horno, en relación con el 
circuito de gases, el ponente citó los clásicos: el directo (con o sin tolva de almacenamiento) y el semidirecto, en los que los gases de las citadas operaciones se utilizan total o parcialmente como aire primario del horno (en el segundo caso con recirculación), y el indirecto (con tolva de almacenamiento) que es el elegido en general por la industria española del cemento en su retorno al empleo del carbón. Analizó las ventajas e inconvenientes de unos y otros en función de los riesgos de autoencendido y explosión, y del rendimiento térmico.

A continuación trató de los distintos tipos de hornos a lo largo de la historia del desarrollo tecnológico del sector industrial del cemento, desde los verticales y los rotatorios largos de vía húmeda, y los Lepol de parrilla con simple y doble paso de gases por vía semiseca, hasta los sistemas de intercambiador con precalcinación, pasando por los intercambiadores internos de calor, de cadenas, cruces, etc. por vía húmeda, y por los intercambiadores de calor en cuatro etapas de ciclones simples o dobles, con circulación en parelelo o en contracorriente, dentro de la vía seca.

Señaló que en esta transición los consumos térmicos específicos y de carbón pasaron de las $1.300-1.500 \mathrm{kcal} / \mathrm{kg}$ de clinker y de los $250 \mathrm{~kg} / \mathrm{t}$ de clinker, respectivamente (habida cuenta del bajo rendimiento térmico de los carbones pobres que se empleaban), en la vía húmeda, a las $750 \mathrm{kcal} / \mathrm{kg}$ de clínker y los $120 \mathrm{~kg} / \mathrm{t}$ de clínker, en la vía seca con intercambiadores de calor. Indicó también las ventajas del acortamiento de los hornos rotatorios y del aumento de las producciones unitarias, así como de la eliminación de la granulación del crudo y de la mejora de la calidad y de la homogeneidad del clínker.

Mencionó también la evolución tecnológica de los enfriadores de clínker, desde los primitivos "satélites" o "planetarios" que daban aire secundario de más baja temperatura y sin posibilidad de regulación, lo que en combustión directa y con ventiladores de baja presión estática producía llamas largas y flojas que dificultaban la conducción del horno, hasta los de parrilla, en los que al aumentar la capacidad de producción de los hornos surgió el problema del aprovechamiento de los gases sobrantes del enfriamiento, lo cual hizo volver a los enfriadores de "satélites", mejorados.

Terminó centrando el interés en los actuales sistemas de hornos con intercambiadores de calor por suspensión del crudo en ciclones, y con precalcinación -descarbonatación- producida en la base del intercambiador de cuatro etapas mediante un quemador que consume del 50 al $60 \%$ del total del combustible, con lo cual se rebaja la carga térmica en la zona de sinterización del horno, en la que el calor se transmite por radiación. En este quemador se emplea el aire a $600-700^{\circ} \mathrm{C}$, sobrante del enfriador de parrilla. Con todo ello, un horno de vía seca transformado y provisto de intercambiador con precalentador puede producir el doble y con menor consumo específico, el cual se puede cifrar en unas $770-780 \mathrm{kcal} / \mathrm{kg}$ de clinker, - de 20 a $30 \mathrm{kcal} / \mathrm{kg}$ más que con los intercambiadores solos-, pero con la ventaja sustancial de que el precalcinador admite cualquier tipo de carbón pobre de bajo poder calorífico, no apto para el quemador principal.

En resumen, el ponente señaló las condiciones de proceso o vía y de tipos de hornos en que habrá de emplearse el carbón para la clinkerización, señalando que los carbones pobres y de baja calidad podrán tener una utilización sólo en los precalcinadores de los hornos con recuperación por intercambiador, que los posean.

\subsection{3. ${ }^{\text {a }}$ PONENCIA, Por el Dr. Jacinto MONGE GUTIERREZ de HUNOSA}

\section{"Aprovechanmiento de Estériles de Carbón para la Industria del Cemento en el Reactor THAGARD”, de HUNOSA.}

Basado en la posibilidad y conveniencia de utilizar como materia prima los cerca de 2,5 millones de $\mathrm{t} / \mathrm{año}$ de estériles de lavadero de carbón que genera HUNOSA, con problemas técnicos, económicos y ecológicos de apilamiento y eliminación, el ponente describió los resultados del 
programa de investigación sobre el reactor de pared fluida a alta temperatura, que llevan a cabo HUNOSA y la THAGARD RESEARCH CORPORATION, USA, orientado en particular a la obtención de clínker.

Señaló que a diferencia de otros reactores tradicionales en que la transmisión de calor se hace por convección y/o conducción, con limitaciones en cuanto a las temperaturas de reacción por la propia resistencia térmica del reactor, y en los que la acumulación de los productos de reacción sobre la pared más caliente -lugar de reacción- merma la capacidad de transmisión de calor de ésta, en el reactor THAGARD se evita el contacto entre reactantes y pared mediante una envoltura o manta de gas, que introducida a través de una pared porosa constituye un lecho fluido. La transmisión de calor a la corriente de reactantes se efectúa por radiación infrarroja a la que es transparente el gas, producida en una primera versión del reactor por una lámpara de Xenon de elevada presión.

Al describir el reactor, indicó sus partes:

i) un núcleo tubular refractario poroso que permite el paso radial del gas, el cual forma una envolvente anular que protege las paredes internas del núcleo y evita el contacto y la deposición de reactantes o productos de reacción sobre él; ii) una camisa que lo envuelve y aisla en un recipiente; iii) unos electrodos entre la camisa y el núcleo que calientan a éste por radiación infrarroja a la temperatura deseada, siendo absorbida la radiación por los reactantes; y iv) un escudo térmico multilaminar que aisla el núcleo y los electrodos dentro de la camisa y evita pérdidas de calor.

Añadió que la temperatura del núcleo se mantenía constante con independencia de la reacción y del flujo de materiales, mediante un circuito que, comandado por un radiómetro óptico, controla la corriente a través de los electrodos; y que al reactor va acoplado un sistema de toma, en tiempo real, de los datos de las variables del proceso, los cuales se acumulan en discos y se muestran en pantalla gráfica, permitiendo determinar consumos y balances de materia y energía y diversas relaciones que pueden ser analizadas después en computador.

Señaló la rapidez de la transmisión de energia en el reactor, determinada por el coeficiente de absorción infrarroja de los reactantes, con temperaturas de operación del orden de $2.000^{\circ} \mathrm{C}$, y con tiempos mínimos de permanencia de los mismos en el reactor.

En cuanto a los estériles de carbón tratados, el ponente indicó que poseian de 80 a $85 \%$ de materia mineral y de 15 a $20 \%$ de materia orgánica, pudiendo esta última ser utilizada como aporte de energía; y que del total de la primera el 70-80\% estaba constituida por minerales de la arcilla y de ellos el $50 \%$ por illita. De los finos, medios y gruesos de estériles procedentes de los distintos lavaderos asturianos el ponente aportó datos analíticos, asi como de las cenizas, de todo lo cual dedujo: i) que no existían grandes diferencias entre fracciones de igual tamaño de distintos lavaderos; ii) que las potencias caloríficas variaban mucho con el tamaño, decreciendo de finos a gruesos en función del contenido de materia orgánica en cada caso; iii) que los contenidos de potasio eran altos de acuerdo con la riqueza en illita; y iv) que las diferencias de composición entre las cenizas de los distintos tamaños eran escasas.

Respecto de la producción de clínker, el ponente dijo que se aprovechó la fracción inorgánica de los estériles de carbón como parte arcillosa de un crudo de cemento portland tipo ASTM-II, mezclada con caliza, cuarcita y mineral de hierro en proporciones adecuadas. Se pretendia con ello: i) probar si con el reactor era posible obtener los constituyentes normales y principales del clinker; ii) estudiar la influencia de la temperatura en la clinkerización; y iii) obtener datos sobre los consumos energéticos y la economía del proceso, y sobre las posibles ventajas de la adición de carbón al crudo.

Según el ponente se barajaron como variables la velocidad de alimentación y la temperatura. 
determinándose en el producto la granulometria, la cal libre y la pérdida al fuego, y analizándolo por difracción de rayos $\mathrm{X}$ y por microscopía óptica. A unos $1.480^{\circ} \mathrm{C}$ no cambia la granulometría del crudo por ausencia de fusión, pero a temperaturas superiores se formaron partículas esféricas más gruesas, apreciándose por rayos $\mathrm{X}$ la presencia de $\mathrm{C}_{3} \mathrm{~S}$ y $\mathrm{C}_{2} \mathrm{~S}, \mathrm{CaCO}_{3}$ sin descomponer, $\mathrm{CaO}$ libre y $\mathrm{SiO}_{2}$; con el microscopio se observaron los dos silicatos y poco material intersticial -fase líquida en la fusión- distinguiéndose el $\mathrm{C}_{3} \mathrm{~A}$ del $\mathrm{C}_{4} \mathrm{AF}$.

De acuerdo con gráficos mostrados por el ponente, para una velocidad de alimentación -y un tiempo de permanencia del crudo en el reactor- la cantidad de $\mathrm{CaCO}_{3} \sin$ descomponer (y la cantidad de clínker formado) tienden a valores asintóticos al crecer la temperatura, lo que hace preciso mayor tiempo de permanencia del crudo en el reactor, o el uso de fundentes y mineralizadores que rebajen la temperatura de formación de fase líquida y permitan en ella la combinación de la cal con los componentes ácidos de la arcilla. En efecto, el aumento del tiempo de permanencia hace crecer linealmente la cantidad real de clinker formada, frente a la teórica, lo que llevó a la conclusión de que con tiempos 3,5 veces mayores - del orden de 2 a 3 segundos- la clinkerización se podía verificar al $100 \%$.

En cuanto al consumo de energía, y aunque no se previó tal estudió, según el ponente se observó que para una velocidad de alimentación de unos $500 \mathrm{~g} / \mathrm{min}$ y una clinkerización del $100 \%$ a unos $2.200^{\circ} \mathrm{C}$ se precisan unas $1.180 \mathrm{kcal} / \mathrm{kg}$ de clínker real. Este rendimiento se mejora variando las condiciones y con la adición de un $30 \%$ de carbón al crudo y con inyección de oxígeno, con lo cual el consumo eléctrico del reactor se redujo casi a la mitad.

Como resumen cabe decir que, en principio, se puede obtener el clínker portland en el reactor THAGARD, a partir de estériles de carbón como componente del crudo, y con rendimientos térmicos mejorables.

\section{Observación del autor de esta reseña:}

Sin embargo, es preciso elegir muy bien los restantes componentes del crudo, en función de la composición de los estériles, para que el crudo total se ajuste a los convencionales en sus módulos o indices, en los grados de saturación y en los standards de cal; así como para que el contenido de fase líquida entre $1.340^{\circ} \mathrm{C}$ y $1.450^{\circ} \mathrm{C}$ sea el conveniente, a cada temperatura del intervalo, para una buena clinkerización. $\mathrm{Y}$ todo ello para trabajar siempre dentro del sistema cuaternario $\mathrm{C}-\mathrm{S}-\mathrm{A}-\mathrm{F}$, en el que los principales -o únicos- constituyentes mineralógicos del clínker sean $\mathrm{C}_{3} \mathrm{~S}$, $\mathrm{C}_{2} \mathrm{~S}, \mathrm{C}_{3} \mathrm{~A}$ y $\mathrm{C}_{4} \mathrm{AF}$. A tal efecto sería conveniente también indagar, en los distintos clínkeres de la etapa experimental, la presencia de especies tales como $C_{2} F, C_{5} A_{3}\left(C_{12} A_{7}\right)$ y algunas otras, en función de las composiciones de los crudos, de las temperaturas alcanzadas en la clinkerización, de los tiempos de permanencia de los crudos en el reactor y del curso (velocidad) del enfriamiento del clínker a la salida de éste.

Sería preciso, asimismo, proceder a un análisis completo del clínker resultante, en el que, además de los conceptos analíticos señalados en la tabla IV del trabajo reseñado, se incluya la cal libre y el residuo insoluble, tal como se determinarian en clínker y cemento. Finalmente sería conveniente determinar el contenido de la fase vitrea del clínker, pues tiene que ver también con la velocidad de su enfriamiento a la salida del reactor, la cual se supone ha de ser grande, ya que ello importa para la calidad y el comportamiento de los cementos. Todo esto podría ser objeto de más profundas y detalladas consideraciones, con vistas a acortar la experimentación de tanteo en el reactor, y a determinar si la operación de éste, con materias primas -aparte de los estériles de carbón- y con composiciones de crudos idóneas, permite obtener clínkeres de calidad, en condiciones económicas y de proceso aceptables. Otro factor a tener en cuenta en tal sentido es la más adecuada finura -granulometría- del crudo de alimentación. 


\subsection{4. ${ }^{a}$ PONENCIA, por el Prof Dr. Francisco SORIA SANTAMARIA, del CSIC/IETCC}

\section{"Influencia de los componentes Minoritarios de los Carbones en la Fabricación de Cementos"}

El ponente introdujo el tema señalando las caracteristicas más importantes de las materias primas $\mathrm{y}$ del crudo de cemento, tanto desde el punto de vista físico como químico y mineralógico, cualitativo y cuantitativo.

Señaló también las condiciones térmicas más destacadas del proceso de clinkerización, en relación con los tipos de vías -húmeda, semiseca y seca- seguidas, así como de hornos -con recuperación térmica por sistemas mecánicos internos, por intercambiadores de parrilla (lecho poroso) o por ciclones-, en cada caso.

Mencionó los procesos sucesivos de deshidratación, descarbonatación y clinkerización (a unos $500^{\circ} \mathrm{C}, 600-1.000^{\circ} \mathrm{C}$ y $1.000-1.450^{\circ} \mathrm{C}$, respectivamente), con formación de una fase líquida (a $1.300-1.450^{\circ} \mathrm{C}$ ). Citó asimismo los tres tipos de combustible empleados: sólido (carbón), líquido (fuel-oil) y gaseoso (gas natural), normalmente empleados en la clinkerización, con tendencia actual y futura al retorno del primero, así como a la eliminación de la vía húmeda, por razones de economía energética.

En cuanto a los combustibles, citó el carbón como utilizado hasta 1949, y el comienzo del empleo del fuel-oil pesado y de los gases natural y de coquería desde dicho año, así como las mezclas de carbón y fuel-oil, y carbón y gas a partir de 1950, hasta que a finales de la década de los 70 se impuso mayoritariamente el fuel-oil (del 75 al $100 \%$ ), incrementándose también en algunos países el uso del gas natural.

Según el ponente los primeros años 80 están siendo de transición, con aumento del consumo de carbón y disminución del fuel-oil, de modo que el cruce de ambos a favor del fuel-oil en el período 60-73, se repite en sentido inverso en el periodo 78-82, aunque de modo más rápido. El fenómeno es general en Europa Occidental.

Seguidamente trató de los componentes minoritarios de los distintos combustibles, de los cuales salvo el $\mathrm{SH}_{2}$ que si abunda exige una desulfuración, está exento el gas natural, mientras que las cenizas del fuel-oil pesado, en proporción de hasta $0,1 \%$ puede contener $\mathrm{SiO}_{2}, \mathrm{Al}_{2} \mathrm{O}_{3}, \mathrm{~K}_{2} \mathrm{O}$, $\mathrm{Na}_{2} \mathrm{O}$, trazas de metales pesados, y cloro elemental y azufre en proporciones medias de $0,05 \%$ y de 2,5 a $5 \%$, respectivamente.

Hizo resaltar la influencia de los álcalis, de los cloruros y del azufre, en el sentido de que los primeros influyen en la emisión de $\mathrm{SO}_{2}$ a la atmósfera, los segundos facilitan la formación de costras y anillos, y el tercero se encuentra en forma de sulfuros, sulfatos y azufre orgánico.

En cuanto a los carbones, hizo destacar su variabilidad en cuanto a su contenido de cenizas (de 3 a $30 \%$ ) y en cuanto a la composición de éstas, en general de naturaleza arcillosa, con cuarzo, pirita y carbonatos, cuyo carácter ácido puede dar lugar a fundidos poco viscosos que con el crudo facilitan la formación de costras, pegaduras y anillos en los hornos.

Señaló que las cenizas obligan a rectificar la composición del crudo y que deben mezclarse homogéneamente con éste, lo que permite la utilización de carbones pobres, sin detrimento del clínker, lo cual se ve favorecido en los hornos con precalcinación.

El ponente pasó después a considerar los circuitos de gases y volátiles en la cocción del crudo, señalando que la corriente gaseosa en el horno arrastra las combinaciones de álcalis, halógenos y azufre formadas por reacción, en fase gaseosa, de los productos volatilizados del crudo y del combustible, las cuales pueden condensarse en las partes frías del horno o del intercambiador, en 
su caso, o hacerlo en los depuradores de gases, dando lugar a los llamados "circuito interno" y "circuito externo", respectivamente; en el primer caso siempre, y en el segundo si el polvo recogido en los depuradores se integra al proceso, la acumulación de tales combinaciones crece en el crudo y en el clinker, hasta alcanzarse un equilibrio entre las aportaciones del crudo, del combustible y de la recuperación, y las, eliminaciones por el clinker y por el polvo y los gases de escape. Por lo tanto, éstos llevarán tanto menos combinaciones a la atmósfera cuanto mayor sea la acumulación de equilibrio, la cual, a su vez, puede dar lugar a depósitos y anillos, por su acción fundente.

Por otra parte, señaló después que el volumen de los circuitos no sólo dependía de la proporción de compuestos volátiles en combustibles y materias primas, sino también del tipo de horno y alimentación, siendo mayor en hornos cortos y con alimentación en polvo, por volatilización más intensa en el caso del polvo y por mayor temperatura en la zona de clinkerización de dichos hornos.

En cuanto a los álcalis en particular, recordó su importancia en la reacción árido-álcalis, en el fraguado y en las resistencias del cemento, lo que en el primer aspecto ha llevado a una limitación de los álcalis totales del cemento, en algunas normas, para ciertos usos con áridos reactivos.

Mencionó que la procedencia de los álcalis es varia y que por lo que respecta a los combustibles, su contenido en ellos dependía de su origen y de su proporción de cenizas, y oscilaba en éstas entre 1 y $6 \%$. Explicó el proceso de su volatilización en forma de óxidos facilitada por: i) la temperatura y el tiempo de permanencia del crudo en la zona de sinterización; ii) por escasez de azufre y óxido de hierro en materias primas y combustibles; iii) por formación de vapor de agua o aportación del mismo en la llama; iv) por abundancia de illita o de mica en el crudo; v) por adición de fluoruros o cloruros al mismo.

$\mathrm{Y}$ concluyó que estos óxidos volatilizados reaccionaban con $\mathrm{SO}_{2}, \mathrm{CO}_{2}$ y $\mathrm{Cl}^{-}$de los gases, formándose sulfatos, carbonatos y cloruros alcalinos, en dicho orden y de mayor a menor temperatura, y condensándose también en dicho orden, en las partes más frías del horno o sobre la alimentación dei mismo, con lo que vuelven al ciclo en circuito interno, o por circuito externo si los compuestos alcalinos menos volátiles recogidos con el polvo en el electrofiltro depurador de gases, se reintegran a la alimentación del horno.

En cuanto al azufre, el ponente mencionó su procedencia y formas de presentación, y la formación de $\mathrm{SO}_{2}$ por combustión, el cual forma sulfatos alcalinos con los álcalis del crudo, vaporizados o no; y sulfato cálcico con la cal de calcinación o con el carbonato del crudo (a falta de álcalis suficientes para fijarlo). Con la primera en el horno a alta temperatura, y con el segundo en el intercambiador o en la instalación de molienda y secado conjuntos, a temperatura más baja.

Respecto a los cloruros, señaló que los aportados por el carbón podian llegar a veces a $0,4 \%$ (frente a $0,3 \%$ aportado excepcionalmente por las materias primas). Los alcalinos formados en fase de vapor y condensados en circuito interno sobre el material de alimentación y en el cuarto ciclón del intercambiador causan perturbaciones del proceso, por lo que se limitan en combustibles $\mathrm{y}$ en materias primas que hayan de ser tratadas en hornos con precalentadores, ya que la supresión de su incorporación por circuito externo apenas produce una reducción de su reciclaje en el circuito interno, la cual exigiria una desviación de gases a la chimenea, sin pasar por el electrofiltro, con merma del buen rendimiento térmico del sistema, principal razón de ser del mismo.

En lo tocante a los fluoruros, el ponente indicó que los carbones suelen contenerlos en menor proporción que los cloruros, y que como éstos dan lugar a procesos cíclicos en circuito interno, pero que al acumularse en el clinker y en el polvo del electrofiltro no daban lugar a perturbaciones.

A continuación trató de las condiciones y limitaciones impuestas por la práctica a los componentes 
volátiles de los circuitos de gases, señalando varios módulos y/o limites para sulfatos introducidos en el crudo y con el combustible, en relación con la formación de costras y anillos y en función de los compuestos de azufre formados, de la proporción de álcalis y de la composición de los gases de escape. En tal sentido desarrolló un ejemplo práctico numérico, según el cual el valor óptimo del "módulo de sulfatos", y por lo tanto el contenido óptimo de azufre del combustible, para un "crudo medio" y con un consumo térmico especifico también medio, viene a ser de $3 \%$ para fuel-oil, lo cual coincide con la realidad en la práctica, y de $1,8 \%$ y de $1,25 \%$, con carbón de $6.000 \mathrm{kcal} \cdot \mathrm{kg}^{-1}$ y lignito de $4.500 \mathrm{kcal} \cdot \mathrm{kg}^{-1}$, respectivamente, lo que indica que, en general, es más frecuente encontrar un defecto que un exceso de azufre en los carbones para la clinkerización, dadas las materias primas y los crudos usuales para la misma. En todo caso, el desequilibrio entre álcalis y azufre -señaló-, se corrige según su signo, añadiendo carbonato sódico o yeso al crudo.

En cuanto al contenido de cloruros en los carbones el ponente señaló que se fija otro limite muy estricto, ya que aquél es mayor que en el fuel-oil o en el gas natural, y que unido a las aportaciones del crudo puede hacer inviable el proceso en hornos con precalentador en suspensión gaseosa.

Con relación a las perturbaciones en la marcha del proceso, indicó que las acumulaciones locales de los compuestos volátiles condensados forman fases fundidas que aglutinan productos sólidos y dan lugar a costras en zonas del sistema con temperaturas inferiores a $1.100^{\circ} \mathrm{C}$, constituidas por sulfatos y carbonatos complejos, asi como por cloruro potásico, de formación inevitable y difícilmente modificable. Algunos de estos sulfatos y cloruros pueden aumentar el espesor del revestimiento o afectar a la calidad del clínker, cuando para reducir el ciclo de los álcalis se introduce azufre con el combustible o yeso con el crudo.

Finalmente el ponente tocó el tema de la emisión de gases contaminantes y polvo en relación con el empleo de carbones, indicando que las posibles anomalias en los humos no eran atribuibles directamente al mismo, sino a marchas anómalas por formación de anillos por reciclado de cloruros o por combustiones imperfectas. Señaló que recientemente se ha hablado de la contaminación por compuestos de talio, no única ni principalmente producida por la combustión de carbones, y mencionó los valores de las emisiones de $\mathrm{SO}_{2}$ y de óxidos de nitrógeno, siendo la de éstos últimos mucho mayor en el caso del gas natural que en el del fuel-oil, y en el de éste mayor que en el del carbón; y que en cualquier fábrica que emplee un mismo combustible dado, la suma de las emisiones de $\mathrm{SO}_{2}$ y $\mathrm{NO}_{x}$ es prácticamente constante.

En conclusión, vino a decir el ponente que dadas las condiciones de proceso en las fábricas modernas, la calidad exigible al clínker y las especificaciones más drásticas en cuanto a contaminación atmosférica se refiere: i) los componentes minoritarios del crudo y de los combustibles (álcalis y más aún azufre y sulfatos) deben ser tomados en consideración, y más particularmente los cloruros en el caso de los carbones; ii) que álcalis y sulfatos deben guardar una relación óptima y no rebasar valores individuales peligrosos, aunque las tolerancias para el azufre del combustible son amplias; iii) que las especificaciones de límites de cloruros en los carbones son mucho más severas, en virtud de las dificultades que aquéllos pueden crear en el proceso; iv) que a pesar de todo son difíciles de evitar, aunque controlables en cierto modo, las formaciones de costras y adherencias acumulativas en zonas frías de la instalación, por debajo de $1.100^{\circ} \mathrm{C}$; y v) que la emisión de polvo y de compuestos volátiles de azufre es prácticamente independiente del tipo de combustible en los hornos modernos, si bien la emisión de óxidos de nitrógeno se reduce con el empleo de carbón.

Como resumen se puede decir que no sólo los parámetros clásicos de los combustibles -poder calorifico, cenizas, volátiles...- son dignos de ser tenidos en cuenta, sino también los componentes minoritarios de los carbones, que pueden afectar de una u otra forma a la calidad del clínker. a la marcha del proceso y a la maquinaria, asi como a la contaminación ambiental. 
3.6. 5. ${ }^{a}$ PONENCIA, por el Prof Dr. Antonio GARCIA VERDUCH, del Instituto de Cerámica y Vidrio del CSIC

\section{"El carbón en las industrias de ladrillos de construcción"}

En su introducción al tema el ponente aludió a la expansión que afectó en los años 60 a la antigua y tradicional industria ladrillera española, con montaje de nuevas instalaciones, sistemas y maquinaria de mayor producción y automatización, y modernización de las existentes, unido todo ello a una mejora de la calidad y de las condiciones de trabajo, y a una mayor preocupación por la protección del medio ambiente.

Una de las consecuencias fue -continuó diciendo- un abandono prácticamente total del empleo del carbón por el del fuel-oil, de más fácil manejo y precio interesante (entonces), hasta el punto de que entre 1965 y 1971 los consumos de carbón y de fuel-oil pasarón de $67 \%$ a $29 \%$, y de $10 \%$ a $46 \%$, respectivamente, siguiendo la misma tendencia en años posteriores, hasta la crisis del petróleo y energética en general.

Con motivo de ésta -prosiguió el ponente- es preciso volver al consumo exclusivo de combustibles sólidos (y en particular del abandonado carbón), con el inconveniente y la dificultad que suponen la inadecuación de los viejos y arrumbados sistemas de combustión de sólidos para las necesidades actuales, lo cual exige la puesta a punto de nuevos sistemas, de la cual se esperan soluciones prácticas. Y precisamente -puntualizó-, para una industria que como la ladrillera une a un gran volumen de producción, un elevado consumo especifico actual, de tal modo que el capitulo energético ha pasado en algunos casos del 25 al $50 \%$ del costo de fabricación, en unos años, lo que hace la situación presente más critica. Soluciones vislumbradas son -añadió-, reconsiderar la adecuación de las pastas arcillosas usuales a esta nueva situación, la incorporación de combustibles a la masa y la utilización de reservas enegéticas de precio bajo.

A continuación el ponente expuso unos datos numéricos del Sector Cerámico de Construcción, referidos a 1978 y relativos a número y tamaño de empresas por capacidades de producción, a producción anual de las mismas, a consumos energéticos específicos total y medio y correspondientes a ladrillos, bovedillas y tejas, así como a los diversos tipos principales de hornos e instalaciones. Destacó de todo ello que la producción, por 1.265 empresas, de unos 18 millones de toneladas, de los cuales aproximadamente un $70 \%$ correspondieron a las 611 empresas, de producción media entre 7.500 y 60.000 t/año, un $20 \%$ a las 633 de baja producción, inferior a 7.500 t/año, y un $10 \%$ a las 21 de gran producción, mayor de 60.000 t/año; que la producción española fue casi 2,3 veces mayor que la francesa, con un predominio de la de ladrillos $(91 \%)$ sobre la de bovedillas $(6 \%)$ y tejas y resto $(3 \%)$; que el consumo energético de toda la producción, de unos 1,3 millones de tep, correspondió a uno medio de fuel-oil de $72 \mathrm{~kg} / \mathrm{t}$ muy alto, siendo mayor el de las tejas (unos $88 \mathrm{~kg} / \mathrm{t}$ ) que el de las bovedillas (unos $70 \mathrm{~kg} / \mathrm{t}$, casi igual al promedio) y que el de los ladrillos (unos $56 \mathrm{~kg} / \mathrm{t}$ ); y que el consumo de los hornos Hoffman fue de unos $66 \mathrm{~kg} / \mathrm{t}$, mayor que el de los hornos-túnel (unos $58 \mathrm{~kg} / \mathrm{t}$ ).

Pasó después a tratar de los combustibles sólidos y de sus sistemas de almacenamiento, preparación y combustión, señalando en cuanto a estas últimas, dos principales alternativas: la de pequeños molinos-inyectores colocados encima del horno, y la de instalaciones centrales de molienda, selección de granos y alimentación de los puntos de fuego, con mayor capacidad de automatización y control y mayor garantía de regularidad de marcha y homogeneidad de producción.

La elección de instalación -prosiguió-, requiere conocer la disponibilidad de combustibles, que habrán de ser de características técnicas aceptables en cuanto a poder calorífico, contenidos de humedad, volátiles, carbono fijo y cenizas; a fusibilidad de éstas; a densidad, temperatura de ignición, abrasividad, etc. Habrán de ser suministrados con regularidad y a buen precio final, incluido el del transporte. 
La instalación -añadió-, que debe ser flexible a cambios de combustible y adaptable a las condiciones de trabajo, debe permitir también toda clase de regulaciones necesarias, ser suficientemente capaz y segura y reunir, en suma, las condiciones suficientes para garantizar una cocción adecuada, homogénea y económica.

Al considerar aspectos de la cocción señabó el ponente la forma de hacerla en paquetes compactos de material crudo, lo cual dificulta la homogeneidad de temperatura y la transmisión de calor; y que para conseguirlas se requerian unas condiciones de finura y granulometria en el carbón y un cierto modo de llevar a cabo la combustión en función del rendimiento térmico, del destino de las cenizas del combustible y de la regularidad y homogeneidad de la producción. Se extendió al respecto en consideraciones sobre la combustión de las partículas de carbón en relación con su tamaño, con su contenido de materias volátiles, con la velocidad con que se inyectan y arden y con el lugar de su combustión en el que ceden su calor, sea en el recinto del horno, o sea en el interior de los paquetes, señalando que, en el segundo caso, se puede conseguir una mayor homogeneización de la temperatura, pero a costa de una atmósfera reductora con peligro de inquemados, decoloración y fusión parcial de las piezas y acumulación de cenizas reactivas, y llegando a la conclusión de que técnica y económicamente es muy dificil conseguir homogeneidad de temperatura en la cocción, y más con los combustibles sólidos.

Trató después el tema de la adición de combustibles a las masas arcillosas en la fabricación de ladrillos, práctica antigua que hoy se aplica con nuevos enfoques, y con aspectos positivos tales como: i) la reducción de gradientes térmicos, la mayor homogeneidad de temperatura y velocidad de cocción, y el acortamiento del ciclo; ii) la posibilidad de utilizar combustibles pobres de bajo precio, como los residuos de la minería del carbón; iii) la posibilidad de actuar sobre el color de las piezas y de obtener piezas ligeras resistentes. Entre los aspectos negativos citó: i) la combustión en condiciones críticas difíciles de regular, proclives a la creación de atmósferas reductoras y a deformaciones y fusiones prematuras de las piezas, por desajustes y subidas de temperatura incontroladas; ii) las modificaciones desfavorables que en el comportamiento de la masa pueden ejercer algunos combustibles pobres añadidos; iii) la posibilidad de obtener productos porosos no deseables $\mathrm{y} / \mathrm{o}$ susceptibles de eflorescer, como consecuencia de una cocción reductora.

El ponente señaló después las limitaciones que el empleo de subproductos como combustibles tiene en la industria ladrillera, y así citó: i) la económica, por los gastos de inversión y/o explotación y/o mantenimiento que ello representa; ii) la de la calidad de la producción, ya que ésta no se puede sacrificar a la utilización de subproductos; iii) la de los suministros, que deben ser suficientes, regulares y de calidad (propiedades) constantes, para poder efectuar las composiciones de masas adecuadas y la realización de los procesos idóneos; iv) la de la contaminación, para que el subproducto utilizado no perturbe ni a la producción, ni al entorno ambiental, ni a la salud de los operarios. Todo lo cual -concretó-, debe ser estudiado con detalle en cada caso particular.

Respecto de los residuos de la mineria del carbón, opinó que la industria cerámica de construcción podría aprovecharlos integramente, previo estudio de los mismos, tanto por el sustrato mineral como por los residuos carbonosos que contienen los estériles. En cuanto a la utilización de éstos señaló dos posibilidades: i) utilizarlos como materia prima exclusiva; ii) mezclarlos con la arcilla en una proporción moderada. En cualquier caso el combustible (barato) que contienen sustituye a una parte equivalente del quemado en el horno (más caro).

En cuanto a los esquistos carboníferos, en los que el carbono se encuentra en forma muy dispersa en una matriz arcillosa, señaló que tienen poder calorífico suficiente y queman bien, sin problemas de mezcla una vez elegidos los adecuados y molidos, pero la cocción con ellos requiere el mantenimiento de una atmósfera oxidante en todo el horno y la eliminación de todo el carbono por combustión. sin reducción. vitrificación. decoloración, deformaciones, agrie- 
tamiento o soldadura de las piezas. Para ello -añadió-, es preciso operar adecuadamente, según el tipo de horno y según el grado de sinterización (o porosidad) que se desee: el uso interno del combustible no permite fuertes sinterizaciones, requiriendo éstas aportación externa de calor.

Citó después, apoyado en cifras, el interes despertado en Francia por el empleo de esquistos en las industrias ladrilleras y de áridos ligeros, indicando que los lodos de lavaderos de carbón se usan como aditivo normal de las pastas cerámicas en alguna región inglesa. Mencionó las condiciones que se deben dar para que a las masas arcillosas se les pueda añadir residuos carbonosos como aditivo: i) mezclar arcillas y/o añadir desgrasantes cuando sea preciso; ii) que la calidad del aditivo carbonoso lo permita y la cantidad añadida del mismo sea la adecuada; iii) que las condiciones de cocción (el ciclo térmico y la atmósfera oxidante) sean los idóneos. Todo lo cual -subrayó-, se debe estudiar y ensayar previamente a escala de laboratorio, y por etapas a escala industrial creciente, hasta ensayar a horno completo en régimen normal. El factor económico de estos estudios -terminó-, se cifra en: i) la máxima proporción de lodo que se puede añadir; y ii) el costo de la termia útil del combustible normal y el de la del lodo puesto en fábrica, habida cuenta de todos los factores que influyen en este último.

Como consideración final el ponente señaló la gravedad del problema energético en la industria ladrillera y la dificultad del retorno a los combustibles sólidos en condiciones distintas a las de antaño, a saber: i) crisis energética que obliga a reducir el consumo específico; ii) estructura industrial que exige mecanización, control y automatización; y iii) crisis económica que restringe la capacidad operativa empresarial.

Como posibles vías de solución apuntó: i) la localización de suministros de combustibles sólidos y la disponibilidad de equipos para su utilización eficaz; ii) la localización de subproductos combustibles incorporables a las masas cerámicas crudas; iii) el uso de las que permitan acortar los ciclos de secado y cocción a menor temperatura y con menor absorción de calor, sin merma de la calidad del producto; y iv) la mejora del rendimiento térmico de las instalaciones.

Como resumen se puede decir que el ponente abordó el tema del retorno al empleo de combustibles sólidos en la industria ladrillera española considerando todas sus dificultades e implicaciones y señalando posibles soluciones técnico-económicas, entre las que destacan la utilización de subproductos combustibles -estériles de la minería del carbón- añadidos a las pastas crudas cerámicas, las modificaciones más idoneas de dichas pastas y la adecuación de los equipos.

\subsection{6. ${ }^{\text {a }}$ PONENCIA, por el Ing. Angel FOMBELlA GONZALEZ, de CERAMICA DEL NALON, S. A.}

\section{"El carbón en la industria cerámica en general"}

Después de hacer una introducción histórica de la cerámica señalando el desarrollo de la misma en Babilonia, donde se empleaba el estiércol como combustible, y mencionando los origenes de las industrias cerámica y calera asturianas en el siglo XVIII, que utilizaban carbones langreanos en sustitución de la leña hasta entonces empleada, el ponente subrayó el auge de la industria ladrillera en los últimos años. Señaló al respecto la sustitución de los viejos hornos por los nuevos agrupados en baterias, y se refirió de modo más concreto a los actuales hornos-túnel, en los que hasta hace poco tiempo se utilizaba como combustible gas o fuel-oil, y que en la actualidad vuelven a emplear carbón.

A continuación describió, en cuanto a dimensiones, producciones y consumos, varios de estos hornos, algunos de los cuales van provistos -dijo- de automatismos para la programación. Señaló diferentes consumos específicos de 550 y $365 \mathrm{kcal} / \mathrm{kg}$ para los hornos-túnel de casi la 
misma longitud y distintas producciones, las cuales son más regulares por la mayor uniformidad de temperatura que se consigue con la atmosfera más homogénea creada mediante el calentamiento lateral en paralelo, a diferencia del realizado por la parte superior, como sucede más generalmente en los hornos de cámara, que también mencionó, en los que se emplean carbones menudos como combustibles, y de los cuales algunos van dotados de microprocesadores que evitan los consumos excesivos de combustibles y el riesgo de deformación de las piezas cerámicas cocidas.

Describió después someramente algunos sistemas de transporte del carbón molido a los mecheros de combustion, bien desde tolvas anejas a éstos, o bien desde una torre central de molienda, según el tipo de calentamiento y horno, mediante tornillos sin fin en el primer caso, y pneumáticamente en el segundo.

Pasó a continuación a mencionar el empleo como combustible de ciertas emulsiones de carbón, fuel-oil y agua en proporciones diversas (50:50 de los dos primeros y 40:40:20\% de los tres, con tendencia a $70 \%$ de carbón y $30 \%$ de agua), citando el caso real de una fábrica de refractarios que cuece a unos $1.500^{\circ} \mathrm{C}$ y utiliza una emulsión de fuel-oil y agua $(70-75 \%$ de fuel-oil y $30-25 \%$ de agua), con resultados alentadores al permitir un cómodo manejo de los mecheros y la utilización de combustibles líquidos de baja calidad, así como la neutralización de compuestos de azufre contaminantes, mediante la cal y la magnesia de las aguas duras añadidas a la mezcla. El ponente vió en estas posibilidades un campo interesante para el empleo futuro del carbón en diversos usos, en sustitución parcial del fuel-oil, propugnando el estudio y el desarrollo del tema por parte del Instituto del Carbón.

Consideró después que tanto la cerámica fina como la refractaria son opuestas en cierta medida al empleo del carbón, por las cenizas y sus impurezas, las cuales contaminan los productos, a los que cada vez se exige una mejor calidad, y entrevió un medio de evitar tales inconvenientes mediante la gasificación del carbón, una vez resuelto técnicamente el problema.

Al tratar de la combustión del carbón en lecho fluidificado, de su desarrollo en el tiempo y de sus aplicaciones progresivas, mencionó su utilización en la calcinación de bauxitas en hornos verticales estáticos, bien aislados térmicamente, en lugar de los tradicionales rotatorios, con ahorros de combustible del 30 al $40 \%$, aparte del ahorro de fuerza motriz. Señaló al respecto el interés que tendría la sustitución de los hornos rotatorios por verticales en la preparación de chamotas y de cal, lo que permitiría asimismo sustituir el fuel-oil por carbón como combustible, evitando la contaminación mediante la captación del polvo en ciclones.

Pasó luego el ponente a tratar de los resíduos hulleros de los lavaderos de carbón, cuyas escombreras perjudican a la ecologia y suponen riesgos por desprendimiento. Consideró la posibilidad de utilizar tales resíduos arcillosos como materia prima cerámica, ahorrando gastos de extracción de arcillas de yacimiento y energía de cocción, dado que el contenido de carbón de los mismos permitiria la autococción del producto, para lo cual deberían ser estudiados y diseñados los hornos más idóneos.

Tocó también el tema de los áridos ligeros utilizados en construcción de hormigón, cuya ligereza debida a una gran porosidad, reduce el peso propio de los elementos y estructuras y favorece el aislamiento térmico y de la humedad, con las consiguientes ventajas. Indicó que para la fabricación de estos áridos ligeros serían aprovechables los materiales de muchas escombreras que podrian ser tratados en hornos verticales, previa nodulación.

Como otras posibles aplicaciones de los residuos hulleros mencionó la obtención de alúmina como materia prima refractaria, y la utilización de aquéllos para obtener crudos de cemento.

Finalmente señaló como última posible aplicación de los estériles mineros del carbón, su adición 
a las tierras de labor como correctores de las mismas, por su efecto protector de las raices en condiciones climáticas extremas, subrayando el interés que tendría un estudio científico del tema.

En resumen, el ponente describió una serie de posibles aplicaciones de los residuos hulleros estériles de la minería del carbón, en diversos aspectos relacionados más o menos directamente con la industria cerámica, e incluso al margen de ella, preconizando su investigación. Señaló también el interés de desarrollar el estudio de la combustión más idónea de dichos estériles, y de los sistemas de hornos más adecuados para ella, según las diferentes finalidades perseguidas.

\subsection{COLOQUiO de la Sesión V}

Tuvo lugar conjuntamente el de las seis ponencias reseñadas, con diversas intervenciones a cargo de los Sres. J. I. ARTIEDA, S. CALDERON, J. LEZANA, A. MARTINEZ..., entre otros varios, a los que respondieron los Sres. ALONSO, CALLEJA, FOMBELLA, GARCIA VERDUCH, MONGE, PEREZ ALONSO y SORIA, miembros del Panel de la Sesión V.

Las preguntas y respuestas versaron principalmente sobre la incidencia de las cenizas del carbón, según su tamaño, composición y modo de incorporarse al crudo, en la calidad y homogeneidad del clínker y del cemento; sobre el efecto de la longitud y forma de la llama, dependiente de la naturaleza del carbón -de su contenido de volátiles y de su finura, entre otras variables-, en la marcha de los procesos de combustión y de clinkerización y en la conducción de los hornos; sobre las esperanzas del reactor THAGARD en cuanto a viabilidad y economía del proceso de clinkerización a escala industrial real, $\mathrm{y}$ en cuanto a la calidad del clínker resultante; sobre el problema de importación de carbones extranjeros, respecto de los paises de origen, de la calidad, regularidad y puntualidad de los suministros, de las estaciones portuarias de recepción y de las instalaciones de mezcla y homogeneización de carbones, de los sistemas de transporte por barco y de distribución interior, y de los almacenamientos del carbón en fábrica de cemento; sobre la influencia que la tendencia a la baja en los precios del carbón en el mercado europeo occidental podría tener en el mercado exterior e interior del carbón, en el caso de España; etc.

El coloquio fue todo lo extenso que permitió el escaso tiempo disponible para el mismo.

\section{INTERVENCIONES EN OTROS COLOQUIOS}

En el Coloquio de las Sesiones I y II, relativas a "Los Recursos Españoles de Carbón: Distribución y Calidades", y a la "Explotación Racional de los Carbones Españoles" respectivamente, tomarón parte, entre otros, representantes del Sector Cementero español: los Sres. S. CALDERON, J. CALLEJA, A. MARTINEZ..., a los cuales respondieron los Sres. ARTIEDA, FELGUEROSO..., entre otros miembros del Panel conjunto.

Las preguntas y observaciones hechas, así como las respuestas recibidas, se refirieron a circunstancias relativas a mercados, precios, suministros y calidades de los carbones nacionales y de importación, principalmente.

Ante la mención hecha por alguno de los ponentes acerca de la oportunidad de establecer un arancel sobre los carbones de importación por parte del Estado, con lo cual -según se dijo- éste ahorraría muchas divisas (dólares pagados por el mismo a precios superiores a los de cotización), si bien compensando de alguna manera al Sector Cementero, uno de los participantes en el Coloquio hizo la observación siguiente:

$\mathrm{Si}$, en el caso de fijar un arancel semejante no se compensase de algún modo satisfactorio y automáticamente el gravamen que tal medida supondría en el precio del cemento español para la exportación, se correría el riesgo seguro de que ésta se viera sustancialmente mermada por la 
competencia de otros paises en los mercados del área mediterránea (Norte de Africa y Oriente Próximo y Medio) y del área americana (del Norte, del Centro y del Sur). Competencia que se ejercería, en cuanto a precio, por paises como Grecia y Turquía que ya se interesan por exportar y hacen propaganda, incluso de carácter técnico, para ello (caso de Grecia); y en cuanto a precio y calidad, por parte de otros paises tales como Francia, Italia y eventualmente Bélgica, con gran producción cementera y/o con experiencia y tradición exportadora de cemento.

Con ello se dejarian de ingresar por el Estado grandes cantidades de divisas -dólarescorrespondientes a un volumen de exportación del orden de los 13 millones de toneladas/año a finales de 1982, lo que supone en números redondos la mitad de la producción española en la actualidad.

Esta merma de ingresos no sería ni con mucho compensada por el ahorro resultante del establecimiento del arancel, con lo cual éste se convertiría para el Estado en una medida ahorrativa a la inversa, es decir, contraproducente. Al margen de ello, la pérdida de al menos una parte del mercado internacional y del consiguiente prestigio de la industria cementera española en el mundo, por una parte podria ser -seria con toda certeza- irreversible; y por otra parte crearía una supersaturación del mercado interior que se encontraría con una producción doble de la que el consumo puede absorber, con las consiguientes consecuencias.

Al tenerse que rebajar por ello la producción, el aprovechamiento de la capacidad total de la misma -cuarta de Europa Occidental y séptima mundial, que en algunos momentos de 1982 ha llegado a ser la segunda de Europa Occidental-, se reduciría en forma peligrosa para la estabilidad del Sector Cementero.

A esta intervención respondió el Panel considerando la lógica de las anteriores observaciones y haciendo algunas matizaciones a ellas en las varias y distintas respuestas dadas.

\section{RESUMEN Y CONCLUSIONES DE LA SESION V: Industrias Básicas del Carbón: CEMENTO Y CERAMICA}

El desarrollo de la Sesión V del Coloquio-Panel sobre el "Futuro de los Carbones Españoles", dedicada a las Industrias del Cemento y de la Cerámica, dentro de las Industrias Básicas del Carbón, tuvo lugar en la tarde del viernes 17 de septiembre de 1982.

En dicha Sesión se presentaron seis trabajos, cuatro concernientes a temas relacionados con el Sector Cementero y dos referentes al Sector Cerámico, precedidos de una Introducción General a cargo del Presidente de la Sesión, Sr. CALLEJA CARRETE.

Fueron Ponentes en ella, por orden de intervención, los Sres. PEREZ ALONSO, ALONSO OBESO, MONGE GUTIERREZ, SORIA SANTAMARIA, GARCIA VERDUCH Y FOMBELLA GONZALEZ; los cuatro primeros por el Sector Cementero y los dos últimos por el Sector Cerámico.

El denominador común del contenido de todas las ponencias fue la repercusión que en las respectivas industrias sectoriales tiene el empleo de carbones como combustibles, y la influencia de la calidad y características de los mismos en la marcha de los procesos y en la calidad de los productos, así como en la economía de la fabricación de los mismos.

Del contenido de dichas ponencias y del animado y amplio Coloquio a que las mismas dieron lugar, se pueden extraer las siguientes conclusiones:

1. Que cada sector industrial, en función de sus características, exige a los carbones unas 
cualidades y unas calidades mínimas para la buena marcha de los procesos, desde puntos de vista técnicos y económicos.

2. ${ }^{\text {a }}$ Que sería de desear, tanto por parte del Sector Minero del Carbón como por los Sectores Cementero y Cerámico, que los carbones españoles fueran tales que su utilización por parte de estos últimos pudiera ser del ciento por ciento.

3. ${ }^{a} \quad$ Que en el caso de no ser asi, y para evitar el tener que recurrir a una importación total del carbón utilizado en cementeria, se debería estudiar la posibilidad de mezclas de carbones nacionales y carbones de importación, con la mayor proporción posible de los primeros, de tal manera que pudieran quedar satisfechas al máximo las necesidades y las aspiraciones de ambos sectores.

4. a Que existan en todo momento garantías de suministro regular, en calidad, cantidad y puntualidad en los plazos, por parte del Sector Minero del Carbón a los Sectores Cementero y Cerámico.

5. Que para todo ello sería necesario establecer un diálogo amplio, continuado y fecundo entre ellos, de modo que para una fábrica de cemento o de cerámica determinadas, o para fábricas de una misma empresa o firma, o para las de una determinada zona del pais, pudiera venirles la solución, siquiera parcial, de la mina o minas más proximas.

En resumen:

Dentro de la satisfación plena de las necesidades de los Sectores Cementero y Cerámico en cuanto a carbones, y de las posibilidades de satisfacerlas que tenga el Sector Minero del Carbón en cada caso, habrá que procurar reducir al mínimo el empleo del carbón de importación y elevar al máximo el del carbón nacional.

\section{CONCLUSIONES DE OTRAS SESIONES*}

\subsection{De la Sesión I:}

"Los recursos españoles de carbón, distribución y calidades"

1. ${ }^{a} \quad$ Según el inventario de Recursos de Carbón Español, las reservas del mismo en 1978 eran de 720 Ttep.

2. ${ }^{\text {a }}$ En los últimos cuatro años el incremento de la investigación geológica, consecuencia en parte de las ayudas del PEN, han permitido incrementar las reservas a un ritmo de 25 Mtep/año como mínimo, lo cual, unido a los recursos existentes, permite esperar se alcancen en unos 20 años los 1.300 Mtep de reservas, siempre que como mínimo se mantenga la actual inversión en investigación.

3. ${ }^{\text {a }}$ El ritmo de incremento de las reservas explotables a cielo abierto ha sido mayor, pudiéndose ya asegurar unos recursos de 420 Mtep, que en su mayor parte podrán pasar a reservas.

4. ${ }^{\mathrm{a}} \quad$ Los 1.300 Mtep de reservas permitirán alcanzar hacia 1988 una producción de 24 Mtep y mantenerlas hasta el año 2020.

* Los textos correspondientes a estas Conclusiones, salvo algún ligero retoque por parte del autor en algún caso, responden a los facilitados por los Presidentes de las respectivas Sesiones. Los citados retoques afectan sólo a la forma. 
5. ${ }^{\text {a }} \quad$ La participación en la producción de las explotaciones mineras a cielo abierto, medida en termias, es del $40 \%$, tendiendo a aumentar. Es posible que llegue a alcanzar el $50 \%$.

6. ${ }^{\mathrm{a}} \quad$ En todas las consideraciones anteriores se supone que las condiciones de demanda, precios $\mathrm{y}$ oferta de mano de obra sean favorables, y que la futura y necesaria legislación ecológica sea razonable.

7. ${ }^{a}$ Existe el temor generalizado de que, de mantenerse el pequeño incremento de la demanda energética, en el reparto de la misma el carbón nacional quede en desventaja en relación con otras energias.

\subsection{De la Sesión II:}

\section{"Explotación racional de los carbones españoles"}

1. ${ }^{\text {a }}$ Destaca la importancia de los problemas de la investigación geológica como apoyo directo a la explotación minera, al tratar aspectos tan señalados para su implantación y desarrollo como los criterios y objetivos alcanzables, la metodologia y los tipos de trabajo, los equipos y medios necesarios, y las técnicas utilizables y sus tendencias futuras.

2. ${ }^{\text {a }}$ Se ha justificado la necesidad de una investigación tecnológica como respuesta para la solución de unos problemas que surgen inexorablemente en la explotación de cualquier yacimiento y, en especial, de los de la franja noroccidental española, en los que las difíciles condiciones geológicas y mineras hacen que sean de muy dificil transplante las técnicas habituales en otros yacimientos con condiciones más favorables.

3. ${ }^{a}$ Se precisa una investigación fundamental en campos tales como la Mecánica de Rocas, la Mecánica de Fluidos, las Atmósferas Explosivas, etc., de las que surgiŕan soluciones para el sostenimiento de galerías y talleres, para las redes de ventilación o para la lucha contra los fuegos, los incendios o el polvo de carbón.

4. ${ }^{a}$ Se precisa también una investigación de nuevos sistemas y métodos de laboreo, así como del desarrollo de los equipos necesarios para hacer operativos dichos métodos.

5. ${ }^{a}$ Se precisa, finalmente, una investigación para la aplicación de nuevas tecnologias, tanto en campos como la Electrónica y la Informática, como en el de la conversión del carbón y la valoración de estériles.

6. ${ }^{\mathrm{a}} \quad$ Se propugna que los protagonistas de estas investigaciones, principalmente en el desarrollo de nuevos sistemas y métodos de laboreo, sean las propias Empresas Mineras y también los Constructores de Maquinaria. El problema se plantea en zonas como puede ser la de la provincia de León, de escasa concentración, en las cuales es necesario proceder a la agrupación de pequeños empresarios y recurrir a la colaboración de entidades y organismos más amplios, o a la colaboración con las Grandes Empresas Mineras, que deben en este sentido ejercer un papel de "lider" en la zona.

\subsection{De la Sesión III:}

"Tecnología en desarrollo y posible aplicación a los carbones españoles"

1. ${ }^{a} \quad$ El crecimiento industrial en España y consiguientemente el del nivel de vida y la disminución del paro están intimamente ligados al crecimiento de la demanda del carbón, equilibrando su producción e incluso superándola. 
2. ${ }^{a} \quad$ Este crecimiento requiere una especial atención a la mejora de rendimientos, a la disminución de costos y a la creación de nuevas industrias o preductos.

3. ${ }^{\mathrm{a}} \quad$ La adopción escalonada de tecnologías en desarrollo, dentro de los procesos de combustión, de lavado o de conversión (especialmente de gasificación del carbón) será muy importante para conseguir los objetivos expuestos.

4. ${ }^{\mathrm{a}} \quad$ Sin embargo no es posible ni técnica ni económicamente limitarse a esperar resultados de los desarrollos tecnológicos fuera de España, basados en carbones no nacionales.

5. Por ello se debería organizar seriamente un programa de investigación cooperativa y aplicada que, al menos, fijara los carbones nacionales a los que se pudiera aplicar cada desarrollo tecnológico, e investigara los parámetros concretos en cada caso y las variables técnicas y económicas aplicables.

\subsection{De la Sesión IV:}

"Industrias básicas del carbón": (A)

\section{CENTRALES ELECTRICAS}

1. ${ }^{\text {a }}$ La industria termoeléctrica ha demostrado su deseo de colaboración incondicional a la solución del problema energético español haciendo un gran esfuerzo inversor para aumentar el consumo de carbones nacionales, habiendo absorbido la caida de la demanda en otros sectores, por lo que ve conveniente la diversificación del compromiso de consumo de los carbones nacionales compartiéndolo con otros sectores industriales.

2. ${ }^{a} \quad$ La producción de energía eléctrica de origen térmico es función de la demanda y del régimen hidrológico, debiendo estar el consumo de carbón ligado a estos factores.

$3 .^{a} \quad$ Actualmente, $y$ en cumplimiento del deseo de colaboración señalado, mantiene almacenadas cantidades muy importantes de carbón, pese a haber fallado en buena parte los compromisos de financiación. Mientras los almacenamientos excesivos continúen, debe mantenerse integramente la línea de financiación. En caso contrario dichos almacenamientos deberán reducirse aceleradamente, lo que incidiria en las compras futuras.

4. ${ }^{\text {a }} \quad$ Las actuales regulaciones legales en lo referente a contaminación son soportables, pero si al intensificarse el consumo de carbones térmicos estas regulaciones se hiciesen más estrictas, producirian una carga de capital muy importante y difícilmente sostenible, junto con una baja de rendimiento de las centrales.

5. ${ }^{\text {a }}$ La utilización de nuevas tecnologías puede mejorar el estado actual, aumentando los rendimientos y las flexibilidades de operación de las plantas por establecimiento de procesos de combustión en lecho fluidificado o de gasificación.

\section{SIDERURGIA}

1. ${ }^{\text {a }} \quad$ La optimización de mezclas permite la mayor utilización de carbones nacionales o de carbones de importación con calidad inferior. Estos estudios han conducido al desarrollo de una tecnologia de apoyo que se está exportando.

2. $\quad$ Las adiciones de productos distintos del carbón (aceites, breas, residuos petroliferos) ayuda a un abaratamiento en el costo del coque y colabora también en el sentido apuntado en la conclusión anterior. 
3. $\quad$ La utilización de nuevas tecnologias, especialmente el precalentamiento de los carbones, colaboran a un aumento de productividad de las coquerias y a una mejora de la calidad del coque.

4. ${ }^{a} \quad$ El estudio de la homogeneización de mezclas garantiza la uniformidad de propiedades del coque, colaborando a extender el consumo siderúrgico de carbones a productos de más bajas calidades y precios.

\section{CALDERAS DE VAPOR Y OTROS USOS}

1. a La combustión en lecho fluidificado es una alternativa en cuanto al rendimiento $\mathrm{y}$ al control de la contaminación, por lo que debería extenderse la investigación en este campo, la cual habria de ser realizada de forma cooperativa.

2. ${ }^{a} \quad$ Los métodos de combustión en lecho fluidificado facilitan la retención de azufre, disminuyendo las causas de contaminación. Se espera que la utilizacion industrial de lechos fluidificados operantes a presión atmosférica o a altas presiones sea un hecho en un plazo de 3 a 5 años.

\subsection{De la Sesión V:}

“Industrias básicas del carbón": (B)

\section{INDUSTRIA CEMENTERA E INDUSTRIA CERAMICA}

Las conclusiones son las señaladas en el Punto 5 de esta reseña.

\subsection{De la Sesión VI:}

"Perspectivas internacionales de producción, comercio y utilización del carbón"

1. ${ }^{\text {a }}$ El desarrollo futuro del carbón dependerá en el mundo y en España, en primer lugar, de la evolución de la demanda de energía; y, en segundo lugar, de la capacidad del carbón para sustituir a otras fuentes de energía y, muy en especial, a los derivados del petróleo en los diversos sectores consumidores de energía.

El incremento en la participación del carbón, a costa de otras fuentes de energía, necesariamente genera situaciones conflictivas entre los diferentes sectores energéticos, las cuales exigen un arbitraje firme de los órganos competentes.

2. $\quad$ En el caso de España este incremento en la participación del carbón es perfectamente viable cuando se la compara con la de otros paises de Europa. En efecto, la participación del carbón en la producción de energía primaria y de energía eléctrica, tanto en relación con el pasado como con las perspectivas hasta 1990 , es inferior a la de los paises que integran la AIE. Es decir, que en el plano comparativo las previsiones de consumo de carbón no se pueden considerar excesivas. Otro aspecto importante sobre el que reflexionar es la diferente estructura de refino, actual y prevista, entre Europa y España, con producción de porcentajes superiores de fuel en nuestro pais, a pesar de los esfuerzos que se están haciendo para modificar esta estructura.

3. ${ }^{\text {a }} \quad$ La diferencia de coste existente entre la termia de fuel-oil y la de carbón, favorable a este último, se prevé que se mantendrá en el futuro, lo que facilitará la penetración del carbón, no sólo por criterios de diversificación de fuentes, sino también por razones económicas. 
4. ${ }^{\text {a }} \quad$ Las políticas energéticas adoptadas después de 1973 han dado ya resultados positivos en la OCDE, tanto en la eficiencia energética como en la sustitución de fuel-oil por otros combustibles.

5. La producción y comercio español de carbón ha evolucionado de forma paralela a la producción y comercio mundial.

6. ${ }^{a} \quad$ A nivel de cada país dos condiciones son necesarias para asegurar un desarrollo sostenido de la penetración y uso del carbón:

- La continuidad de las políticas a nivel gubernamental y empresarial, como lo exige el largo período de maduración y la cuantía de las inversiones que se relacionan con esta actividad.

- El logro de costos de explotación de minas lo más bajos posible, con vistas a mantener la diferencia de precios con el petróleo. Ello exige desärrollos mineros sełectivos, dando prioridad a aquellas explotaciones que tengan reservas de calidad, explotables a cielo abierto a poder ser, una buena gestión y una buena logistica.

7. ${ }^{a} \quad$ En el caso de España se ha destacado la conveniencia de desarrollar una mayor acción comercial por parte de los productores españoles, en relación con los consumidores actuales y potenciales.

8. ${ }^{\text {a }} \quad$ El desarrollo futuro del carbón todavía puede verse amenazado si se comete el error de adoptar políticas coyunturales basadas en situaciones transitorias de precios de petróleo.

\subsubsection{En el Sector Eléctrico}

1. ${ }^{\text {a }} \quad$ El aumento de la utilización del carbón en la producción de electricidad se realiza, en casi todos los paises de la CEE (excepto la Gran Bretaña), a base de un incremento cada vez más importante del carbón doméstico y de importación, por razones de seguridad, economía y flexibilidad de suministro.

2. ${ }^{a} \quad$ Su trascendencia como servicio público y las cuantiosas inversiones que comporta exigen una seguridad a largo plazo de los suministros de carbón, que sólo puede provenir de productores capaces de garantizar contractualmente la calidad y la cantidad de los suministros por el periodo de vida de la central.

3. ${ }^{\text {a }} \quad$ Ello sólo es posible si se disponen planificaciones a largo plazo, garantizadas por los órganos competentes que aseguren unos mínimos de producción y consumo.

4. ${ }^{\text {a }}$ La calidad del carbón es un factor cada vez más importante, habida cuenta de la repercusión que en el precio final tiene el transporte, y de la economía que se produce en el almacenamiento y combustión de mejores carbones. En este sentido se deberá progresar en estudios de las posibilidades de mejor lavado y mezcla de carbones térmicos.

\subsubsection{En el Sector Cementero}

1. ${ }^{\mathrm{a}}$ Este Sector está prácticamante convertido al carbón y sus instalaciones le permiten una gran flexibilidad para quemar combustibles sólidos, líquidos y gaseosos.

2. a $^{2}$ Dadas las condiciones del mercado de este producto: $50 \%$ en el nacional y $50 \%$ en los de exportación, siempre en libre competencia, los combustibles que utilice en el futuro han 
de responder dentro de unos mínimos de calidad y seguridad de suministro, determinantemente al precio.

3. ${ }^{\text {a }} \quad$ La necesaria ubicación de las plantas cementeras en la proximidad de sus propios mercados y las salidas al mar condicionan, dada la importante incidencia del costo del transporte, el origen de los combustibles y el que éstos sean de la mejor calidad posible.

\subsubsection{En el Sector Siderúrgico}

1. ${ }^{\text {a }} \quad$ Las perspectivas derivadas de los estudios para la reestructuración del sector siderúrgico nacional en su vertiente de consumidor de carbones coquizables indica, para las diversas alternativas y horizontes analizados, que los consumos previstos no difieren sustancialmente de los producidos en los últimos años.

Paralelamente la estructura de aprovisionamiento del exterior, aunque no es muy diversa en la actualidad, será homogénea para todo el Sector y coherente con la estructura de la oferta mundial.

2. ${ }^{\text {a }} \quad$ Se considera que toda la producción de carbón coquizable que pudiera ofertar la minería española sera absorbida sin problemas por la siderúrgia.

\section{CLAUSURA}

En el acto de clausura del Coloquio-Panel, presidido por Don José Manuel GARCIA VERDUGO, Presidente del Consejo General de Castilla y León, intervinieron en primer lugar el Decano del Colegio Oficial de Químicos de Madrid, Don Ovidio LAGUNA CASTELLANOS y el Presidente de la Asociación Nacional de Quimicos de España, Don Baldomero LOPEZ PEREZ, el cual hizo la presentación del Director General de Minas, Don Adriano GARCIALOYGORRI. Este pronunció la conferencia de clausura en la que hizo destacar las ayudas que la Administración, dentro del Plan Energético Nacional, ha venido prestando durante 1982 al Sector Minero del Carbón, las cuales habrán rebasado al término del año un total de treinta y cinco mil millones de pesetas. Señaló también la necesidad de mejorar la calidad de los carbones nacionales manteniendo al mismo tiempo la relación precios/mercados, si se quiere ganar la batalla a la importación. Esta -dijo- debe ser complementaria, tanto cualitativa como cuantitativamente considerada.

El Sr. GARCIA VERDUGO, finalmente, agradeció la justificada elección de León como sede del Coloquio-Panel, y participando del optimismo general respecto del futuro del carbón, señaló la preocupación, compartida por él, de cuantos dependen y van a depender de la riqueza carbonifera de la zona y de su futuro, solicitando la ayuda de todos para la solución de estos problemas.

A continuación declaró clausurado el Coloquio-Panel sobre "El Futuro de los Carbones Españoles". 